\title{
BIOFABRICATION OF SILVER NANOPARTICLES USING LEAVES OF GLORIOSA SUPERBA AND ITS ANTICANCER PROPERTIES
}

\author{
MURALI SATYANARAYANA BETHU ${ }^{1,2}$, VENKATESWARA RAO J1* \\ ${ }^{1}$ Department of Toxicology, Division of Pharmacology and Toxicology, CSIR-Indian Institute of Chemical Technology, Hyderabad, Telangana, \\ India. ${ }^{2}$ Academy of Scientific and Innovative Research, CSIR - Indian Institute of Chemical Technology, Hyderabad, Telangana, India. \\ Email: jviict@gmail.com \\ Received: 01 June 2017, Revised and Accepted: 12 July 2017
}

ABSTRACT

Objective: We aimed to synthesize the cost effective, one pot and an eco-friendly technique for the green synthesis of silver nanoparticles (AgNPs) using $1 \mathrm{mM}$ of silver nitrate $\left(\mathrm{AgNO}_{3}\right)$ solution through the aqueous leaf extracts of Gloriosa superba (GS) reducing and capping agent and its anticancer activity.

Methods: Synthesis briefly $95 \mathrm{~mL}$ of $1 \mathrm{mM} \mathrm{AgNO}_{3}$ was taken into amber colored conical flask and added $5 \mathrm{~mL}$ of aqueous leaf extract of GS (pale brown) and incubated at room temperature in dark condition for about $24 \mathrm{hrs}$. Characterization of AgNPs derived from GS (GS-AgNPs) was performed with physiochemical techniques (ultraviolet, transmission electron microscope [TEM], X-ray diffraction [XRD], and thermal gravimetric analysis) and cytotoxicity by 3-(4,5-dimethylthiazo-2-yl)-2,5-diphenyltetrazolium bromide assay.

Results: We synthesized cost effective, eco-friendly AgNPs were characterized by physiochemical techniques. The crystal nature of AgNP was studied by XRD. TEM studies reveal the morphology of GS-AgNPs, the size of the nanoparticle is 10-50 nm. The cytotoxicity of GS-AgNPs studied against the four human cancerous cell line DU145, SKOV3, PC3, and A549 but the GS-AgNPs are most sensitive toward the SKOV3 cell line. The minimum inhibitory concentration (IC) is $79.45 \pm 5.26,61.80 \pm 4.27,94.74 \pm 9.26$, and $90.10 \pm 8.24 \mu \mathrm{g} / \mathrm{mL}$, respectively. Morphological assessment of the SKOV3 cells was studied using $\mathrm{AO} / \mathrm{EB}$ and Hoechst staining at $\mathrm{IC}_{50}$ concentration.

Conclusion: The bio fabrication of the GS-AgNPs were simple, eco-friendly and one pot synthesis, it is used as an anticancer agent in future, pending further investigation.

Keywords: Gloriosa superba, Silver nanoparticles, Characterization, Cytotoxicity.

(c) 2017 The Authors. Published by Innovare Academic Sciences Pvt Ltd. This is an open access article under the CC BY license (http://creativecommons. org/licenses/by/4. 0/) DOI: http://dx.doi.org/10.22159/ajpcr.2017.v10i11.20389

\section{INTRODUCTION}

In general, nanoparticles are prepared by a variety of chemical and physical methods which are quite expensive and potentially hazardous to the environment, which involve the use of toxic and dangerous chemicals that are responsible for various biological risks. Among the all noble metal nanoparticles, the products of silver nanoparticles (AgNPs) have shown supremacy due to their wide range of applications with unique properties such as chemical stability, good conductivity, catalytic, and most important biological properties. These AgNPs are being successfully used as antibacterial [1], antiviral [2], antifungal [3], anti-inflammatory [4], and wound healing [5]. Recently, AgNPs are emerging as promising agents for drug delivery in cancer therapy [6]. To avoid the adverse effects on humans and to the environment, alternative eco-friendly biosynthetic methods using either microorganisms or plant extracts have gained importance as a simple and viable alternative to chemical synthetic procedures and physical methods [7].

The phytonanotechnology is an emerging field in the last two decades, due to their huge applications in the fields of physics, chemistry, biology, and medicine [8-10]. Many plants such as Pelargonium graveolens [7], Medicago sativa [11], Cinnamomum camphora [12], Emblica officinalis [13], Diospyros kaki [10], Carica papaya [14], Coriandrum sp. [15], Tridax procumbens, Jatropha curcas, Solanum melongena, Datura metel, and Citrus aurantium [16] have shown the potential of reducing silver nitrate $\left(\mathrm{AgNO}_{3}\right)$ in the formation of AgNPs. The advantages of using plant and plant-derived materials for biosynthesis of metal nanoparticles have attention toward researchers for understanding the possible mechanism of metal nanoparticle formation and enhancing biological properties of the plant material [17].

Therefore, in this work, we have aimed another approach for green synthesis of AgNPs using Gloriosa superba (GS) leaf extract. It is Ayurveda herb used for hundreds of years for the treatment of muscular pain, joint inflammation and pain disorders found widely in South India, whose leaves are rich in alkaloids and poly phenolic compounds, which can play key role as a strong reducing agent in the reaction. The active compounds in plant which was responsible for the potent antiproliferative activity have been reported. Colchicine from GS is an active compound could be given the highest proliferative activity against the SKOV3 cells. The genus of this plants species has been reported for their anticancer, antioxidant, and antifungal [18] properties. Hence, anticancerous properties of these biosynthesized Ag-nanoparticles were tested against human prostate cancer (DU145 and PC-3), ovarian carcinoma (SKOV3), and lung carcinoma (A549). Furthermore, we have conducted to provide the direct evidence of the cytotoxic strength of Gs-AgNPs using various physiochemical and microscopic Analysis.

\section{EXPERIMENTAL SECTION}

\section{Chemicals and antibodies}

RPMI-1640 medium, Dulbecco's modified Eagle's medium (DMEM) and $\mathrm{AgNO}_{3}$ were obtained from Sigma-Aldrich (St. Louis, USA). Fetal bovine serum and antibiotics were obtained from Gibco (Thermo Fisher Scientific, Grand Island, NY, USA). All other chemicals were purchased from Sigma wherever not specified. 


\section{Plant material and preparation of extract}

The leaves of GS was collected from Talakona forest ranges of Tirumala Tirupati Hills (north latitudes $18^{\circ} 10^{\prime}$ to $19^{\circ} 44^{\prime}$ and east longitudes of $82^{\circ} 53^{\prime}$ to $84^{\circ} 05^{\prime}$ ), Andhra Pradesh, South India. The plant was identified by the renowned plant Taxonomist at Osmania University, Hyderabad. Initially, the $100 \mathrm{~g}$ of leaves were thoroughly washed with normal water, followed by autoclaved Milli-Q water. The cleaned leaves were crushed using mortar and pestle and transferred to a beaker filled with $200 \mathrm{~mL}$ of Milli-Q water. The mixture was boiled 2-3 times for 3 minutes each at 30 minutes interval ( $800 \mathrm{~W}, \mathrm{LG})$ using a microwave oven, kept under vigorous stirring and centrifuged at 12,000 g for 10 minutes. The supernatant was stored at $4^{\circ} \mathrm{C}$ used as capping and reducing agent and maintained sterile condition throughout the experiment.

\section{Biosynthesis of AgNPs}

Biosynthesis of AgNPs was carried out according to the method described by Mukherjee et al. [19]. Briefly: About $95 \mathrm{~mL}$ of $1 \mathrm{mM} \mathrm{AgNO}_{3}$ was taken into amber colored conical flask and added $5 \mathrm{~mL}$ of aqueous leaf extract of GS (pale brown) and incubated at room temperature in dark condition for about 24 hrs. The synthesis of AgNPs was primarily detected by observing the solution for color change from pale yellow to brown.

\section{Characterization of GS-AgNPs}

GS-AgNPs were thoroughly characterized by several physicochemical techniques. Initially, $100 \mathrm{~mL}$ of mixture were centrifuged for 40 minutes at $14,000 \mathrm{~g}$ at $15^{\circ} \mathrm{C}$ using KUBOTA 6930 centrifuge. The intense loose black colored GS-AgNPs pellet was utilized for further characterizations and in vitro experiments.

\section{Ultraviolet (UV)-visible spectroscopic analysis}

The UV-visible spectrum of the AgNPs, synthesized by plant extract of GS was recorded from 300 to $800 \mathrm{~nm}$ on a UV-visible double beam spectrophotometer (Spectra MAX Plus; Molecular Devices; supported by SOFTmax PRO-5.4).

\section{X-ray diffraction (XRD) technique}

The crystal nature of the AgNPs was determined using XRD analysis. The glass slide having a cavity was used as a sample holder. The XRD pattern of NPs was recorded on PANalytical Empyrean operated at a voltage of $40 \mathrm{kV}$ and current of $30 \mathrm{~mA}$ using CuK $\alpha$ radiation $\left(\lambda=1.5406 \mathrm{~A}^{\circ}\right)$. The diffractometer was controlled with Datascan software and the scan parameters set were scan rate $1.2 / \mathrm{min}$ and scan range $2 \theta=0-80^{\circ}$.

\section{Transmission electron microscope (TEM) analysis}

The size and shape of the AgNPs was carried out using TEM. All the reaction mixtures were subjected to ultra-sonication and a drop of the reaction mixture was placed over carbon-coated copper grids and the drop was dried with a $100 \mathrm{~W}$ infrared lamp (JEOL JSM-2100F operated at $200 \mathrm{kV})$.

\section{Thermo gravimetric analysis}

The lyophilized powder sample of GS-AgNPs synthesized from GS leaf extract was subjected to thermal gravimetric analysis (TGA) using TGA Q500 Universal TA instrument (UK). For this analysis, about 10-15 mg of sample was taken in a crucible, heated at a constant heating rate of $10^{\circ} \mathrm{C} \mathrm{min}^{-1}$ in nitrogen gas atmosphere from ambient temperature, $25-700^{\circ} \mathrm{C}$ under continuous flow of nitrogen at the rate of $30 \mathrm{~mL} \cdot \mathrm{min}^{-1}$.

\section{Cell lines and cell culture}

The human prostate cancer (DU145 and PC-3), ovarian carcinoma (SKOV3), and lung carcinoma (A549) cell lines were obtained from the National Centre for Cell Sciences, Pune, India. Cells were grown in either RPMI 1640 (PC3) or DMEM (DU145, SKOV3 and A549). The media was supplemented with $10 \%(\mathrm{v} / \mathrm{v})$ heat-inactivated fetal bovine serum, 100 units/mL penicillin, and $100 \mu \mathrm{g}$ streptomycin per mL. All cell lines were maintained in culture at $37^{\circ} \mathrm{C}$ in an atmosphere of $5 \% \mathrm{CO}_{2}$.

\section{Cytotoxicity assay in vitro}

Exponentially, growing cells $\left(2 \times 10^{4}\right.$ to $3 \times 10^{4}$ cells $\left./ 100 \mu \mathrm{L}\right)$ were seeded in 96-well plates and incubated for $12 \mathrm{hrs}$. Cells were then treated continuously by the addition of test compound (GS-Ag nanoparticles in $100 \mu \mathrm{l}$ of media) to obtain final concentrations of $10-100 \mu \mathrm{g} / \mathrm{mL}$. After $24 \mathrm{~h}$, cell survival was evaluated by adding $10 \mu \mathrm{L}$ of $5 \mathrm{mg}$ of 3-(4,5-dimethylthiazo-2-yl)-2,5-diphenyltetrazolium bromide (MTT) per $\mathrm{mL}$ in phosphate-buffered saline (PBS) (pH 7.4). After 3-4 hrs of incubation at $37^{\circ} \mathrm{C}$, the medium and the MTT were removed and $100 \mu \mathrm{L}$ of dimethyl sulfoxide was added to dissolve the precipitate of reduced MTT. The formazan crystals were then dissolved, and the absorbance was determined at $570 \mathrm{~nm}$ with a microplate reader (Spectra MAX Plus; Molecular Devices; supported by SOFTmax PRO-5.4). The MTT assay distinguishes between viable and nonviable cells on the basis of the requirement of physiologically active mitochondria to metabolize the MTT only in viable cells. The inhibitory concentration $50 \%\left(\mathrm{IC}_{50}\right)$ was calculated as the concentration of GS-Ag nanoparticles causing a 50\% inhibition in absorbance compared to that of cells treated with media alone.

\section{Morphological changes of cells}

The altered morphology of cells $\left(1 \times 10^{5}\right)$ at different concentrations of GS-Ag nanoparticles $\left(\mathrm{IC}_{25}, \mathrm{IC}_{50}\right.$, and $\left.\mathrm{IC}_{75}\right)$ were studied after $24 \mathrm{hrs}$ using an inverted phase contrast microscopy (Optika, Italy). Simultaneously, another batch of cells were washed with PBS $(0.01 \mathrm{M}, \mathrm{pH} 7.4)$ and fixed the cells in $70 \%$ ethanol for $2 \mathrm{~h}$ at $4^{\circ} \mathrm{C}$. Later, cells were stained individually with $10 \mu \mathrm{L}$ of $100 \mu \mathrm{g} / \mathrm{mL}$ Hoechst 33,342 solutions and $5 \mu \mathrm{L}$ of $100 \mu \mathrm{g} / \mathrm{mL}$ AO-EB in a dark chamber for 30 minutes at room temperature. Then, the stained cells were washed 3 times with PBS and observed using a fluorescence microscope with standard filters.

\section{RESULTS AND DISCUSSION}

The genus of GS is belongs to Liliaceae family and contain rich in alkaloids. The genus of this plants have been reported to processes anticancer, antioxidant, and antifungal [18]. GS is an endemic undershrub found in Talakona forest range hills of Andhra Pradesh, South India. The aqueous extract (5 mL) of the GS leaves extract was added to $95 \mathrm{~mL}$ of $1 \mathrm{mM} \mathrm{AgNO}_{3}$ solution at $45^{\circ} \mathrm{C}$ to form AgNPs. GsAgNPs inhibited the growth of four different human cancer cell lines (DU145, SKOV3, PC-3, and A549), at a minimum IC of IC F0 $_{50} 79.45 \pm 5.26$, $61.80 \pm 4.27,94.74 \pm 9.26$, and $90.10 \pm 8.24 \mu \mathrm{g} / \mathrm{mL}$. The anticancerous properties exhibited by these particles could be related to the alkaloid and secondary metabolites of the extract.

\section{Characterization}

\section{UV-visible absorption studies}

The synthesis of AgNPs using leaf extracts of GS was evident by a change in the color of $1 \mathrm{mM} \mathrm{AgNO}_{3}$ solution from pale yellow to brown, which was monitored by the UV-Vis spectroscopy [20], ranging from 200 to $800 \mathrm{~nm}$ (Fig. 1). The leaf extract solution exposed to $\mathrm{AgNO}_{3}$ ions shown a significant absorption at around $430 \mathrm{~nm}$, whereas leaf extract alone did not show any evidence of absorption in the range of 350-750 nm. This may be due to the excitation of surface plasmon resonance (SPR) and the reduction of $\mathrm{AgNO}_{3}$. Earlier reports have also confirmed that the SPR of AgNPs exhibited maximum peak at $420 \mathrm{~nm}[20,21]$. To the best of knowledge, this was the first report on biosynthesis of AgNPs using GS. Green synthesized GS-AgNPs were stable for 3 months without shifting the surface plasmon absorbance band. This suggests that the phytochemical present in GS leaves acts as a reducing agent and capping agent.

\section{TEM}

Bio-fabricated AgNPs size and shape was studied using TEM. The TEM images of the GS-AgNPs shown in Fig. 2 demonstrated further insight into the morphology and size details of the synthesized AgNPs. The nanoparticles were spherical shape and with average diameter ranging $10-50 \mathrm{~nm}$. 


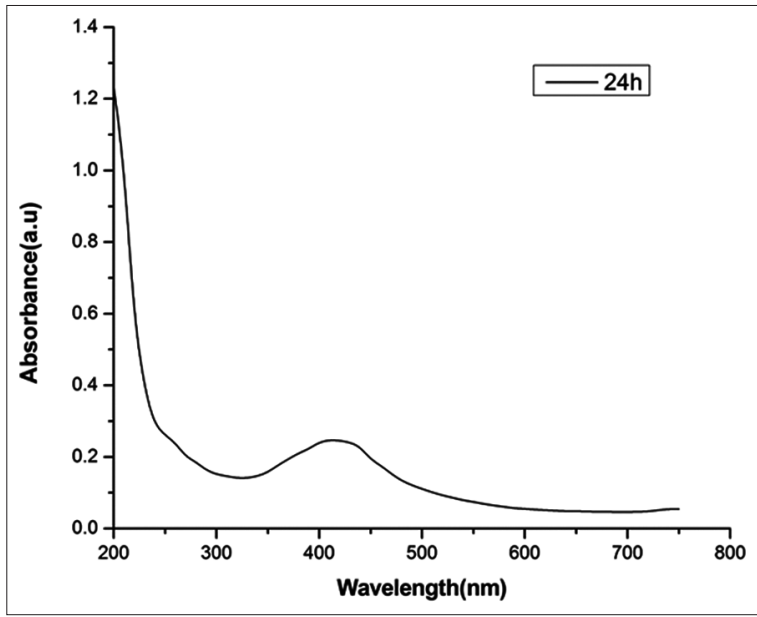

Fig. 1: Ultraviolet-visible absorption spectrum at $24 \mathrm{hrs}$ of newlysynthesized silver nanoparticles using leaf extracts of Gloriosa superba

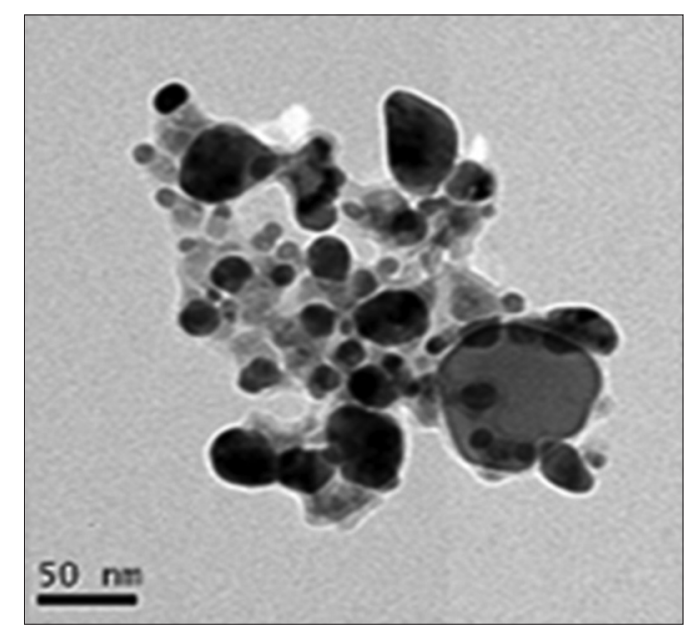

Fig. 2: Transmission electron microscopic image of Gloriosa superba-silver nanoparticles at $50 \mathrm{~nm}$ range

\section{$X R D$}

The crystalline nature of nanoparticles was confirmed by X-ray crystallography. The XRD pattern of the synthesized GS-AgNPs is shown in Fig. 3. Three strong Bragg reflections at $38.14^{\circ}, 44.33^{\circ}$, and $64.56^{\circ}$ corresponds to the planes of (111), (200), and (220), respectively; which can be indexed according to the facets of face centered cubic crystal structure of silver. All these diffraction patterns are (111), (200), and (220) consistent with standard data files (JCPDS Card no 04-0784). It is indicating that synthesized AgNPs are in pure crystalline nature. Earlier similar findings have been reported for AgNPs [22].

\section{Thermo gravimetric analysis and zeta potential measurement}

The TGA thermogram of GS leaf extract synthesized AgNPs, shows three steps of total weight loss that indicates the increase in stability of NPs. The initial loss till $157.05^{\circ} \mathrm{C}$ could be indicative of the moisture content present on the AgNPs. The other two major losses at 292.37 and $651.04^{\circ} \mathrm{C}$ could be assigned to the degradation alkaloids and proteins, respectively (Fig. 4). TGA give the evidence for the conjugation of photochemical from plant extract due to the variation in the temperature loss and also give the stability to the nanoparticles. Zeta potential plays an important role in determination of stability of the nanoparticles. Dried AgNPs re-suspended in the water and zeta potential of the GS-AgNPs were determined. They indicate the overall charge that the particle acquires in a particular medium and the charge is present on

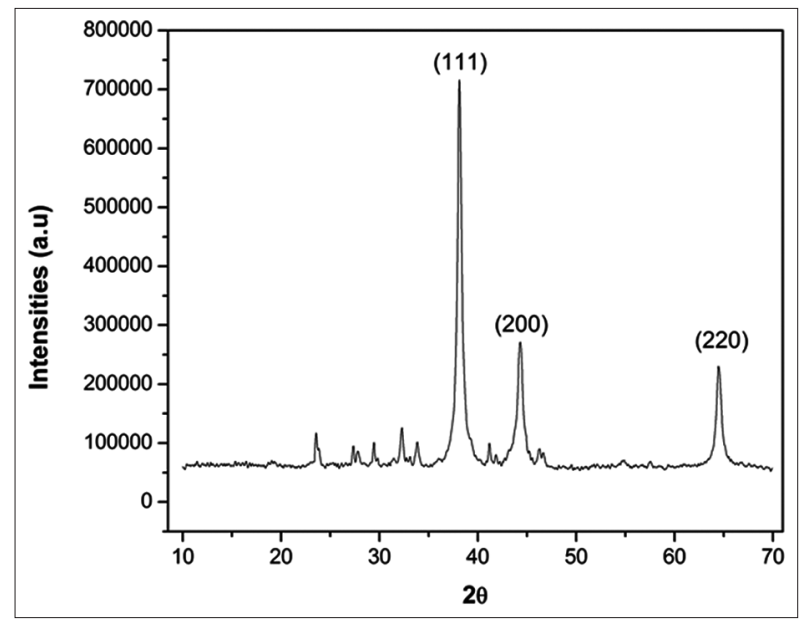

Fig. 3: X-ray diffraction spectrum of biosynthesized nanoparticles

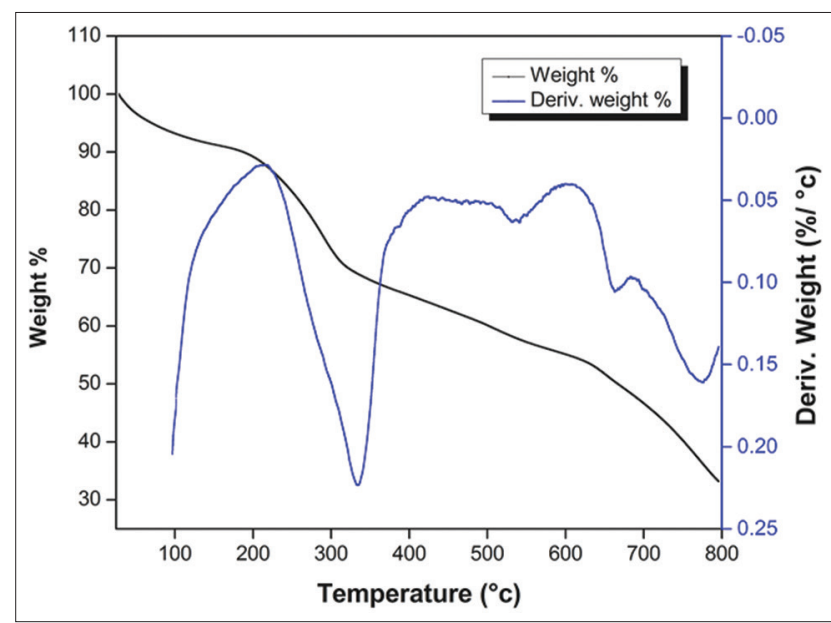

Fig. 4: Thermo gravimetric analysis of Gloriosa superba-silver nanoparticles

the surface of the biogenic nanoparticles that will generate repulsive forces between the nanoparticles. The synthesized GS-AgNPs showed an anionic charge with a potential value of $-29.8 \mathrm{mV}$. The high negative potential value supports long term stability, good colloidal nature and high dispersity of AgNPs due to negative-negative repulsion [19].

\section{GS-AgNPs in cancer regulation}

AgNPs synthesized with GS leaf extracts exhibited potent cytotoxic activity against DU145 and PC-3 (human prostate cancer cell lines), SKOV3 (human ovarian carcinoma cells), and A549 (human lung carcinoma cells). Chemically synthesized AgNPs were used as a positive control. The cytotoxic effects of these nanoparticles at 24 hrs treatment the number of viability (live cells) was measured by the MTT assay and $\mathrm{IC}_{50}$ values calculated for each cell line. Gs-AgNPs induced $50 \%$ cytotoxicity at $79.45 \pm 5.26,94.74 \pm 9.26,61.80 \pm 4.27$, and $90.10 \pm 8.24 \mu \mathrm{g} / \mathrm{mL}$, respectively, indicating concentrationdependent cytotoxicity. It is evident from Fig. 5 that GS-AgNPs exhibit significant inhibition SKOV3 cells with an $\mathrm{IC}_{50}$ value of $61.80 \mu \mathrm{g} / \mathrm{mL}$. Nevertheless, these nanoparticles are less toxic to most common mammalian cells (Chinese hamster ovary [CHO] cells) up to $300 \pm 18.29 \mu \mathrm{g} / \mathrm{mL}$. Similar findings were noticed when AgNPs synthesized with leaf extract of Sesbania grandiflora and rhizome extract of Acorus calamus demonstrated to be cytotoxic to MCF-7 and A431 carcinoma cells, respectively [23,24]. Biologically synthesized AgNPs showed high inhibitory effect against various cancer cell lines at higher concentration. DNA damage is one of the major incidents that take place during apoptosis. AgNPs perform well as cancer 


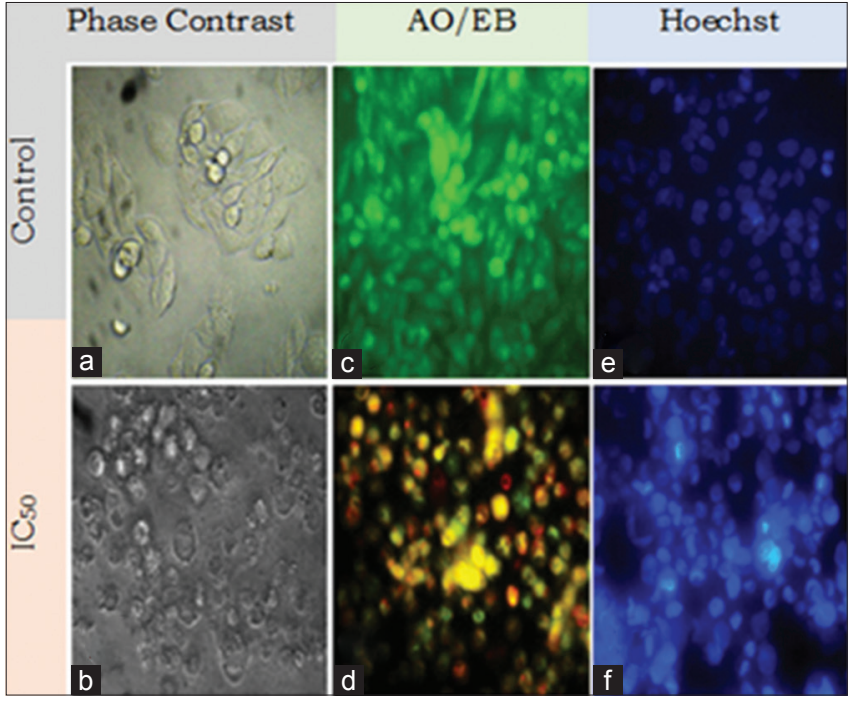

Fig. 5: The effect of inhibitory concentration $50 \%$ concentrations of Gloriosa superba-silver nanoparticles (GS-AgNPs) on

SKOV3 cells for 24 hrs exposure $(\times 400)$, ( $a$ and b) Phase contrast microscopy, (c and d) AO/EB staining, and (e and f) Hoechst staining. Intact cells in control (a, c, e). Cells with green color in AO/EB staining represents viable cells (c), yellow staining represents early apoptotic (d), and reddish staining represents late apoptotic cells (e). Pale and bright cyan colors in Hoechst staining indicates as an early and late apoptosis (f)

therapeutics because they can disrupt the mitochondrial respiratory chain, which induces the generation of reactive oxygen species, and ATP synthesis, which can induce DNA damage [25-27]. In this study, several morphological characteristics including the disruption of membrane integrity, decreased cell growth, cytoplasmic condensation, and cell clumping, were observed in SKOV3 cell treated with $\mathrm{IC}_{50}$ concentrations of GS-AgNPs, whereas control cells remained active (Fig. 4). AO/EB fluorescent DNA binding dye indicated different DNA states in viable and apoptotic cells [28]. Cells stained green represent viable cells, whereas yellow staining represents early apoptotic cells, and reddish or orange staining represents late apoptotic cells. Cells treated with lower concentration $\left(\mathrm{IC}_{50}\right)$ of GS-AgNPs showed early apoptosis and showed late apoptotic features. Hoechst staining clearly indicated as an early apoptosis leading to the margination of chromatin into a horseshoe shaped structure followed by apoptotic blebbing on cell surface treated with $\mathrm{IC}_{50^{\circ}}$. Similar, findings were reported earlier against the breast cancer cells induced by green synthesized AgNPs [29].

\section{CONCLUSION}

We fabricated plant-mediated AgNPs (GS-AgNPs) using aqueous plant extract of GS via a rapid, facile, green, and eco-friendly method. The secondary metabolites present in the plant extract served as a both reducing and stabilizing agent. The synthesized GS-AgNPs were highly stable and did not exhibit toxicity toward the normal cell line (CHO). The bio-synthesized GS-AgNPs have proved to be potent cytotoxic agents against (DU145 and PC-3, SKOV3, A549) the plausible apoptotic changes were explained against the most susceptible cell line (SKOV3).

\section{REFERENCES}

1. Murugesan S, Bhuvaneswari S, Sivamurugan V. Green synthesis, characterization of silver nanoparticles of a marine red Alga spyridia fusiformis and their antibacterial activity. Int J Pharm Pharm Sci 2017;9(5):192-7.

2. Mori Y, Ono T, Miyahira Y, Nguyen VQ, Matsui T, Ishihara M. Antiviral activity of silver nanoparticle/chitosan composites against H1N1 influenza A virus. Nanoscale Res Lett 2013;8(1):93.

3. Panácek A, Kolár M, Vecerová R, Prucek R, Soukupová J, Krystof V, et al. Antifungal activity of silver nanoparticles against Candida spp.
Biomaterials 2009;30(31):6333-40.

4. Wong KK, Cheung SO, Huang L, Niu J, Tao C, Ho CM, et al. Further evidence of the anti-inflammatory effects of silver nanoparticles. ChemMedChem 2009;4(1):1129-35.

5. Gunasekaran T, Nigusse T, Dhanaraju MD. Silver nanoparticles as real topical bullets for wound healing. J Am Coll Clin Wound Spec 2012;3(4):82-96.

6. Renugadevi K, Venusaswini R. Microwave irradiation assisted synthesis of silver nanoparticle using Azadirachta indica leaf extract as a reducing agent and in vitro evaluation of its antibacterial and anticancer activity. Int J Nanomater Biosci 2012;2(2):5-10.

7. Sankar R, Karthik A, Prabu A, Karthik S, Shivashangari KS, Ravikumar V. Origanum vulgare mediated biosynthesis of silver nanoparticles for its antibacterial and anticancer activity. Colloids Surf B Biointerfaces 2013;108:80-4

8. Armendariz V, Torresdey JL, Yacaman MJ, Gonzalez J, Herrera I, Parsons JG, et al. Gold nanoparticle formation by oat and wheat biomasses. In: Proceedings of Conference on Application of Waste Remediation Technologies to Agricultural Contamination of Water Resources; Kansas City, Mo, USA; 2002.

9. Raveendran P, Fu J, Wallen SL. A simple and "green" method for the synthesis of $\mathrm{Au}, \mathrm{Ag}$, and $\mathrm{Au}-\mathrm{Ag}$ alloy nanoparticles. Green Chem 2006;8:34-8.

10. Song JY, Kim BS. Rapid biological synthesis of silver nanoparticles using plant leaf extracts. Bioprocess Biosyst Eng 2009;32(1):79-84.

11. Gardea-Torresdey JL, Gomez E, Peralta-Videa JR, Parsons JG, Troiani H, Jose-Yacaman M. Alfalfa sprouts: A natural source for the synthesis of silver nanoparticles. Langmuir 2003;19(4):1357-61

12. Huang J, Li Q, Sun D, Lu Y, Su Y, Yang X, et al. Biosynthesis of silver and gold nanoparticles by novel sundried Cinnamomum camphora leaf. Nanotechnology 2007;18(10):1051-64.

13. Ankamwar B, Damle C, Ahmad A, Sastry M. Biosynthesis of gold and silver nanoparticles using Emblica officinalis fruit extract, their phase transfer and transmetallation in an organic solution. J Nanosci Nanotechnol 2005;5(10):1665-71.

14. Mude N, Ingle A, Gade A, Rai M. Synthesis of silver nanoparticles using callus extract of Carica papaya - A first report. J Plant Biochem Biotechnol 2009;18(1):83-6.

15. Nazeruddin GM, Prasad NR, Prasad SR, Shaikh YI, Waghmare SR, Adhyapak P. Coriandrum sativum seed extract assisted in situ green synthesis of silver nanoparticle and its anti-microbial activity. Ind Crops Prod 2014;60:212-6.

16. Rajasekharreddy P, Rani PU, Sreedhar B. Qualitative assessment of silver and gold nanoparticle synthesis in various plants: A photobiological approach. J Nanopart Res 2010;12(5):1711-21.

17. Iravani S. Green synthesis of metal nanoparticles using plants. Green Chem 2011:13:2638-50

18. Aranya M, Hiroyuki A, Worapong K, Toshihiro A, Worapaka M, Jiradej M. Potent ant proliferative effect on liver cancer of medicinal plants selected from the Thai/Lanna medicinal plant recipe database “MANOSROI III". Evid Based Complement Altern Med 2015;2015:11.

19. Mukherjee S, Chowdhury D, Kotcherlakota R, Patra S, Vinothkumar B, Bhadra MP, et al. Potential theranostics application of bio-synthesized silver nanoparticles (4-in-1 system). Theranostics 2014;4:316-35.

20. Sivalingam P, Antony JJ, Siva D, Achiraman S, Anbarasu K. Mangrove Streptomyces sp. BDUKAS10 as nanofactory for fabrication of bactericidal silver nanoparticles. Colloids Surf B Biointerfaces 2012;98:12-7

21. Kirthi AV, Rahuman AA, Jayaseelan C, Karthik L, Marimuthu S, Santhoshkumar T, et al. Novel approach to synthesis silver nanoparticles using plant pathogenic fungi, Puccinia graminis. Mater Lett 2012;81:69-72.

22. Chandrappa CP, Chandrasekar N, Govindappa M, Shanbhag C, Singh UK, Masarghal J. Antibacterial activity of synthesized silver nanoparticles by Simarouba glauca against pathogenic bacteria. Int J Curr Pharm Res 2017;9(4):19-22.

23. Das J, Paul Das M, Velusamy P. Sesbania grandiflora leaf extract mediated green synthesis of antibacterial silver nanoparticles against selected human pathogens. Spectrochim Acta A Mol Biomol Spectrosc 2013;104:265-70.

24. Nayak D, Pradhan S, Ashe S, Rauta PR, Nayak B. Biologically synthesised silver nanoparticles from three diverse family of plant extracts and their anticancer activity against epidermoid A431 carcinoma. J Colloid Interface Sci 2015;457:329-38.

25. Asharani PV, Low G, Mun K, Hande MP, Valiyaveettil S. Cytotoxicity and genotoxicity of silver. ACS Nano 2009;3:279-90.

26. Morones JR, Elechiguerra JL, Camacho A, Holt K, Kouri JB, 
Ramírez JT, et al. The bactericidal effect of silver nanoparticles. Nanotechnology 2005; 16:2346-53.

27. Antony E, Sathiavelu M, Arunachalam S. Synthesis of silver nanoparticles from the medicinal plant Bauhinia acuminata and Biophytum sensitivum - A comparative study of its biological activities with plant extract. Int J Appl Pharm 2017;9(1):22-9.
28. Preethi R, Padma PR. Anticancer activity of silver nanobioconjugates synthesized from piper betle leaves extract and its active compound eugenol. Int J Pharm Pharm Sci 2016;8(9):201-5.

29. Von White G $2^{\text {nd }}$, Kerscher P, Brown RM, Morella JD, McAllister W, Dean D, et al. Green synthesis of robust, biocompatible silver nanoparticles using garlic extract. J Nanomater 2012;2012. pii: 730746. 